\title{
OS LIMITES E AS POSSIBILIDADES DAS PRÁTICAS RESTAURATIVAS ENQUANTO ALTERNATIVA PARA A SUPERAÇÃO DA VIOLÊNCIA DE GÊNERO CONTRA A MULHER SOB A ÉGIDE DO ABOLICIONISMO PENAL
}

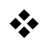 \\ Marli M. Moraes da Costa \\ Universidade de Santa Cruz do Sul - UNISC - Brasil \\ Rosane Porto \\ Universidade de Santa Cruz do Sul - UNISC - Brasil
}

\section{Resumo}

O referido artigo tem por finalidade convidar o leitor a refletir sobre a utilização de outras práticas restaurativas, como o círculo de construção de paz nos casos de violência de gênero. A premissa inicial está ao se fazer uma análise crítica da Lei Maria da Penha - Lei 10340/2006, sob a égide do abolicionismo penal, se quer com isso, afirmar que a abordagem da mencionada lei ao não dar voz e vez de escuta ao homem, demonstra ser uma lei de caráter exclusivamente punitivo.

Palavras-chave: práticas restaurativas, violência contra a mulher, abolicionismo penal

\section{Considerações iniciais}

Com o advento da Lei Maria da Penha em 2006, a violência contra as mulheres, em especial o femicídio passou a ter visibilidade na sociedade, diga-se de passagem, passou a ser intolerável, bem como a cultura patriarcal se fragilizou diante do poder feminino, que labuta historicamente para compartilhar espaços de poder com o homem. Por outro lado, ainda é incipiente a força feminina, pois as próprias mulheres culturalmente ainda estão revestidas pelo patriarcado, o que sufoca e as confunde nas suas subjetividades. É interessante trazer a baila aqui, o fato que o movimento feminista teve suas peculiaridades nos principais locais do mundo, cite-se: na França, nos Estados Unidos e na América do Sul. A distinção que se faz a respeito dessas peculiaridades, assenta-se que tanto na França quanto nos Estados Unidos a luta fora pelos direitos políticos e aqui na 
América do Sul, o movimento parece ter se reduzido ao debate ou enfrentamento da violência.

Não se quer deixar de reconhecer com isso, a importância de enfrentar o fenômeno multifacetal da violência, que reside em um dos seus axiomas, no fato de os homens não compreenderem ou assim desejarem manter-se, quando as mulheres, querem ocupar o espaço público, decidir sobre a reprodução da prole e sobre o libido. Ou seja, a partir do instante em que as mulheres começam a perceber e reconhecer que são sujeitos sociais, com direito a condição humana, não mais de escravas ou submissas de uma cultura patriarcal, que as reduziu a função materna e doméstica, pelo motivo de existir, alguns homens não aceitam e consequentemente querem manter seu poder não só simbolicamente, mas pela materialização da violência.

Por outro lado, buscar pela via da lei ou restringir o direito a lei com o fito de enfrentamento e inibição de atos de barbárie dos homens contra as mulheres, não rompe com o ciclo da violência e nem garante as mulheres o empoderamento e a liberdade de exercer sua cidadania dentro do espaço público, bem como do doméstico, sendo que nesse ela na sua maioria exerce a função de chefe e zelo pela prole ${ }^{1}$. É preciso ter cuidado com a lógica da lei que pode virar uma perpetuação da lógica punitiva ou não declarada. Não se quer com isso, afastar a responsabilização dos comportamentos que afrontam a dignidade do outro, mas quer atentar os pensadores para repensar os aspectos culturais além do direito delimitado pela lei e sim ir ao encontro da transdisciplinariedade pelo pensamento da complexidade.

Nesse contexto é que se dão os seguintes questionamentos: É possível trabalhar com os homens autores de violência de gênero luz das práticas restaurativas sob a perspectiva do abolicionismo penal? Por conta disso, tratar-se-á do abolicionismo penal e seus contributos para desconstrução da lógica punitiva que também se reproduz com o homem: agressor da mulher e protagonista na Lei Maria da Penha, no que tange a responsabilização ou criminalização da sua conduta. O abolicionismo retira a resposta fácil buscada exclusivamente pela aplicação da lei, faz os sujeitos pensarem alternativas de enfrentamento a violência e fomentam a cultura da paz. E para construir uma cultura de paz é preciso que os indivíduos internalizem os valores éticos voltados a coletividade e ao respeito pela diversidade.

\footnotetext{
${ }^{1}$ CARLOTO, Cássia Maria. Ruptura ou reforço da dominação: gênero em perspectiva. São Paulo. Prefeitura Municipal. Coordenadoria Especial da Mulher; Secretaria do Governo Municipal. Políticas públicas e igualdade de gênero / Tatau Godinho (org.). Maria Lúcia da Silveira (org.). - São Paulo: Coordenadoria Especial da Mulher, 2004, p.188.
}

Barbarói, Santa Cruz do Sul, Edição Especial n.44, p.<177-203>, jul./dez. 2015 


\section{$1 \mathrm{O}$ abolicionismo penal: aspectos conceituais}

Muitos pensadores, entre eles Michel Foucault trataram das vulnerabilidades do sistema prisional, desconstruindo o pensamento do poder dominante: da pena como castigo ou a recuperação do indivíduo. Os que realmente ingressam e são punidos nas prisões são aqueles segregados pela sociedade, desnecessários, excluídos e invisíveis. A lógica punitiva foi pensada para deixar atrás dos muros das prisões, os pobres, os negros alforriados, enfim os indesejáveis pela elite dominante das sociedades.

Com efeito, o patrimonialismo negativo pode ser entendido como o uso do poder político para prejudicar ou efetivamente discriminar determinados grupos sociais. No Brasil, a discriminação do sistema policial e judiciário contra os grupos mais vulneráveis da população, especialmente contra os negros, tem sido uma constante histórica ${ }^{2}$. Ao encontro disso percebe-se o extremo que ainda vige na sociedade brasileira: "os brancos das casas-grandes e os negros das senzalas"”.

Em meados do século XXI, a sociedade comporta-se como uma sociedade do século XIII, em que no Brasil o sistema penal e o prisional foram articulados para capturar principalmente os negros "fujões". E ainda permanece com seus "capitães do mato" correndo atrás de delinqüentes negros, pobres, prostitutas, deixando de lado os grandes criminosos, brancos e de colarinho branco. Nesse cenário de retrocesso, com estratégias de aprisionamento melhor elaborada, existem os crimes passionais e de ódio cometidos contra as mulheres pelos seus companheiros, pela violação de direitos feminino: direito ao respeito, a cidadania a visibilidade das suas subjetividades.

Para o movimento feminino, a Lei Maria da Penha representou uma conquista simbólica, de visibilidade a mulher, no entanto, ainda se tem muito a avançar, pois mesmo com a legislação os homens não estão deixando de cometer femicídio. Ao encontro disso, é fundamental refletir sobre a legislação enquanto política voltada a questões de gênero, estabelecendo uma análise a partir do abolicionismo penal no sentido de reforçar que a punição contra o agressor reproduz a lógica punitiva do século XVIII, por não recuperá-lo,

\footnotetext{
${ }^{2}$ SORJ, Bernardo. A nova sociedade brasileira. Rio de Janeiro: Jorge Zahar, 2000, p.15-16.

${ }^{3}$ É ilusão supor-se a sociedade colonial, na sua maioria, uma sociedade de gente bem alimentada. Quando à quantidade, eramo-nos em geral os extremos: os brancos das casas-grandes e os negros das senzalas. Os grandes proprietários de terras e os pretos seus escravos. Estes porque precisavam de comida que desse para os fazer suportar o duro trabalho da bagaceira. (FREYRE, Gilberto. Casa-grande \& senzala: a formação da família brasileira sob o regime patriarcal. 52.ed. São Paulo : Global, 2013, p.95).
} 
poucos se conscientizam que a relação de convivência não dá mais para seguir em frente e que deixar livre a mulher também é a sua felicidade.

A partir do século XVIII o ente estatal ganhou a titularidade da ação penal e o direito de punir quem infringisse os padrões comportamentais sociais adequados previstos em normas positivadas. Porém, embasado na coação e na repressão, o Direito concorreu e ainda concorre - para produzir um tipo de sociedade sustentada sobre relações de força e de poder. Daí, a consequência dessa forma de pensar e de agir culminou na estruturação de um modelo punitivo, que encontrou a sua forma de expressão na criação da mais concreta imagem de violência; eleita, justificada e sustentada pelas instituições sociais e políticas dominadoras do poder - como o principal instrumento de resposta aos comportamentos desviantes, a saber: a prisão. Constrói-se aquilo que Foucault denomina de sociedade punitiva, um tipo de sociedade em que o ente estatal executa as funções corretivas, juntamente com as outras funções, chamadas de penitenciárias, reproduzidas pelas práticas de aprisionamento ${ }^{4}$. Nesse panorama, percebe-se que a autodefesa e a autocomposição deixam de serem as únicas formas compositivas de litígios, o que não legitima o Poder Público a punir sem oferecer o devido processo legal e a ampla defesa ao acusado. É pelo processo que se busca tutelar os direitos à vida, à liberdade, à honra e à integridade das pessoas enquanto agentes sociais.

Por outro lado, o que se verificou desde a História Antiga com a justiça privada, compreendendo o período da Idade Média em que se deu a profissionalização da justiça, por influência da civilização romano-germânica e, ainda, a Idade Moderna com as escolas penais clássicas sobre o crime e a delinquencia; é que a vítima comumente esteve na condição secundária. Isso fica demonstrado quando se observa que a estrutura do sistema é voltada para o autor do ato delituoso, ou seja, a preocupação assenta-se na punição desse sujeito. Entretanto, a ideologia de que as pessoas devem sofrer pelo mal que provocaram expande o mal existente no mundo, e a punição por si só, não basta para o restabelecimento do ofensor e da vítima.

Outrossim, o sistema de justiça convencional, na maior parte dos casos, considera o crime como uma transgressão contra os interesses do Estado, sendo que a resposta a essas violações devem ser pagas em prol da sociedade - e não da vítima - sendo definidas por profissionais representantes do ente estatal. $\mathrm{O}$ fato de o Estado e não o indivíduo ser a vítima dificulta a percepção do dano pelo ofensor, por ser uma ideia demasiadamente

4 FONSECA, Marcio Alves da. Michel Foucault e o direito. São Paulo: Max Limonad, 2002. p. 133.

Barbarói, Santa Cruz do Sul, Edição Especial n.44, p.<177-203>, jul./dez. 2015 
abstrata, afasta e exclui a vítima da relação processual, deixando-a impossibilitada de participar da resolução de seu próprio litígio. A esse respeito, são as palavras de Anitua "Mais do que usurpar a função jurisdicional, o Estado e o Direito - o rei e seus juristas especializados - apropriaram-se das relações de poder interpessoais, do próprio conflito. $\mathrm{O}$ monopólio estatal ius puniendi significa que não se substituía somente a sociedade em assembléia, mas também as vítimas de reclamação, e em seus lugares apareceram funções estatais que deviam ser respeitadas por aqueles. O Estado teria o interesse, desde então, na resolução dos conflitos, mais do que os particulares, o que se revelaria em falta de acusações e no surgimento das delações secretas como motor inicial das ações que promoveriam juízos e castigos. ${ }^{5}$

Nesse sentido procura-se demonstrar que o projeto da modernidade é caracterizado pelo equilíbrio entre a regulação e a emancipação. O pilar da regulação é constituído dos princípios do Estado, do mercado e o da comunidade. Por outro lado, o pilar da emancipação é constituído pela articulação da racionalidade moral-prática do direito moderno, da racionalidade cognitivo-experimental da ciência e da técnica modernas e da racionalidade estético-expressiva das artes e da literatura modernas. Dessa forma, o equilíbrio pretendido obtém-se pelo desenvolvimento harmonioso de cada um dos pilares e das relações dinâmicas entre eles. Contudo, ressalta que esse equilíbrio não foi conseguido na medida em que a modernidade se identificou com a trajetória do capitalismo, acarretando o fortalecimento do pilar da regulação em detrimento do pilar da emancipação ${ }^{6}$.

De acordo com Bobbio, uma das funções mais frequentemente atribuídas ao direito é a repressão dos comportamentos desviantes, por meio do direito penal. Para ilustrar essa afirmação, o autor se utiliza de uma comparação entre Direito e Medicina, expondo que, assim como a Medicina, o Direito não possui uma função voltada à prevenção das doenças sociais, mas desempenha uma função terapêutica, voltada a tratar as doenças - o que não pressupõe a cura - depois de já manifestadas ${ }^{7}$.

Para o processo político, o crime é igualmente um instrumento favorável. A manifestação de um posicionamento em relação à criminalidade é uma maneira importante de se inserir no meio social. Logo, os reais problemas e as necessidades que estão por trás

\footnotetext{
5 ANITUA, Gabriel Ignacio. Histórias dos pensamentos criminológicos. Op. cit., p. 43.

${ }^{6}$ SANTOS, Boaventura de Sousa. Pela mão de Alice: o social e o político na pós-modernidade. 3. ed. São Paulo: Cortez, 1997,p.236.

7 BOBBIO, Norberto. Da estrutura à função: novos estudos de teoria do direito. Tradução de Daniela Beccaccia Versiani. Barueri: Manole, 2007. p. 90.
}

Barbarói, Santa Cruz do Sul, Edição Especial n.44, p.<177-203>, jul./dez. 2015 
de um crime são desconsiderados pelo sistema atual, que tem como fundamento a culpa legal - altamente técnica - e não a culpa factual - retirada da experiência ${ }^{8}$.

Nesse viés, Zehr afirma que o principal motivo do fracasso do sistema atual de justiça é a lente pela qual os sujeitos olham o crime, já que se construiu uma visão da realidade que parece ser imutável ${ }^{9}$. Portanto, mister se faz trocar essas lentes violentas e alienadas, transpondo aquilo que se convencionou chamar de habitual, comum e normal, mas que apenas demonstra a insistência humana no erro, no insucesso e na ineficácia de um sistema que raramente pode cumprir com a sua função primordial, ou seja, de reintegração social.

Salienta-se, como contributo na busca pelo rompimento de tais proposições excludentes, eis a Criminologia Crítica, representada pelo paradigma da reação social e da vitimologia que surgem para questionar a postura assumida pelo direito penal, apontando para um processo conciliador entre as partes envolvidas no conflito, pois, à medida que se intensifica os meios de socialização e de construção de consensos, diminui a necessidade das formas tradicionalmente exercidas pelos meios de coação, isto é, do próprio Direito ${ }^{10}$. O redescobrimento da vítima ocorreu, porém, que, com o surgimento da noção de "bem jurídico", surgiu uma objetivação da figura da vítima, deixando ela de ser o sujeito sobre o qual recairia a ação delitiva, que sofreria a conduta delituosa, passando a ser o sujeito portador de um valor, o bem jurídico, exatamente o que, realmente, vem a ser lesado ${ }^{11}$. Nessa seara, Sumariva considera vítima:

a pessoa que sofre danos de ordem física, mental e econômica, bem como a que perde direitos fundamentais, através de atos ou omissões que consistem em violação a normas penais, incluindo aquelas que prescrevem abuso de poder ${ }^{12}$.

Atualmente, Criminologia explica o delito através da perspectiva de conflitos interpessoais. Isto se deve, em especial, à significação que adquiriu na Criminologia a teoria da aprendizagem social e da interação simbólica, também se voltando para a vítima.

\footnotetext{
8 ZEHR, Howard. Trocando as lentes: um novo foco sobre o crime e a justiça - justiça restaurativa. Tradução de Tônia van Acker. São Paulo: Palas Athena, 2008. p. 57-64.

9 Idem, p. 90.

10 BOBBIO, Norberto. Da estrutura à função: novos estudos de teoria do direito. Op. cit., p. 90.

11 SANTANA, Selma Pereira de - Justiça Restaurativa: a reparação como consequência jurídico-penal autônoma do delito/ Selma Pereira de Santana - Rio de Janeiro: Lumen Juris, 2010, p.18.

${ }^{12}$ SUMARIVA, Paulo. Criminologia: teoria e prática. Niterói, RJ: Impetus, 2013, p.51.
} 
O delito é compreendido agora como um processo social, como uma interação entre o delinquente, a vítima e a sociedade. ${ }^{13}$

Diante desse contexto, a sociedade brasileira necessita rememorar sua história de colonização, construir sua identidade para buscar uma forma alternativa de justiça fundada na ética e na cidadania, para o enfrentamento a exclusão social, as desigualdades sociais, com efeito a criminalidade.

Igualmente, a resposta dada ao crime deve levar em conta não somente a obrigação imposta socialmente de ver a justiça realizada, mas, sobretudo, deve considerar a possibilidade de atender as motivações e as necessidades de todos os prejudicados, inclusive as das vítimas. A partir dessa perspectiva, será possível começar a se pensar na instauração de uma cultura societal, capaz de expandir o olhar para o ser humano, além do dano causado pelo delito. Por conta disso, a justiça restaurativa aparece no horizonte do sistema de justiça como uma nova lente, dentro dos seus limites e possibilidades para propor outro caminho. Assim sendo, é importante revisitar as delimitações conceituais trazidas por alguns abolicionistas, em especial Nils Christie que desconstrói a ordem dada pela lei e a indústria do crime.

Christie trabalha dentro de uma lógica crítica, a partir de dados comparativos sobre a realidade carcerária em diversos países, principalmente na Noruega (que já foi exemplo de política criminal humanitária), Austrália, Finlândia, Estados Unidos da América. É bastante impactante saber que os Estados Unidos da América têm a maior ou uma das maiores populações carcerárias. Nessa mesma ordem de pensamento, ao analisar os dados de crescimento e decréscimo dessa população nos mais diversos países, constatase que na sua maioria, a prisão é uma resposta de segregação e punir com dor àqueles que são indesejados pela sociedade ${ }^{14}$.

Entenda-se por indesejados, as pessoas que são de procedência pobre, negra ou imigrantes ou ainda, incapazes de consumir nas sociedades capitalistas;. É interessante saber que nos países como a Noruega em que os formadores de opinião, pensadores da política criminal por meio da Criminologia conheceram a realidade prisional enquanto vítimas do sistema, e por conta disso, preocuparam-se em fomentar e construir políticas

\footnotetext{
13 SANTANA, Selma Pereira de - Justiça Restaurativa: a reparação como consequência jurídico-penal autônoma do delito/ Selma Pereira de Santana - Rio de Janeiro: Lumen Juris, 2010, p.21.

14 CHRISTIE, Nils. A industria do controle do crime. A caminho dos GULAGS em estilo ocidental. Tradução de Luis Leiria. Rio de Janeiro: Forense, 1998, p. 27.
}

Barbarói, Santa Cruz do Sul, Edição Especial n.44, p.<177-203>, jul./dez. 2015 
alternativas de responsabilização as condutas desviantes por outra via, que não a das prisões $^{15}$.

Embora a Noruéga tenha resistido a política das prisões, a sua visão humanista também fora abalada, pois os seus defensores estão sendo substituídos por jovens e estes estão se filiando a lógica penal, que aos poucos está esvaziando dos espaços acadêmicos a própria Criminologia. O que leva o autor a indagar o que aconteceu? Ele sinaliza alguns pontos, entre eles: os representantes da Holanda se tornaram o objeto pessoal da irritação internacional causada pela política em relação às drogas; o país também começa a se adaptar aos padrões europeus, sendo cobrada inclusive no sentido de criminalizar as drogas, a política criminal passa a ser tema de especialistas, afastando a comunidade e criando uma divisão de pessoas comuns e as que são consideradas criminosas, entre outras questões ${ }^{16}$.

Na Holanda também não foi diferente, esse país era a "fortaleza da criminologia na Europa". A maioria das universidades tinham cursos de criminologia ou os cursos de Direito Penal estavam cheios, pelo interesse na Criminologia. No entanto, a pressão internacional fora maior, que interferiu na academia. Segundo o autor a Holanda triplicou sua população carcerária, desde 1975 e a Europa perdeu mais um exemplo de tolerância e respeito ao outro, independentemente da condição que se encontre. ${ }^{17}$ Os Estados de bem - estar em crise, também interferem significativamente no fator da tolerância, pois desfragmenta e segrega aqueles que já encontram-se na margem da pobreza, da exclusão e da desigualdade, por isso, torna-se rentável dentro da lógica capitalista pensar nas prisões enquanto novos campos de concentração, extermínio e segregação dos indesejáveis na sociedade alternativa e de consumo ${ }^{18}$.

Nesse ideário, os países do ocidente deixam de lado políticas européias, inclusive os próprios países europeus, aproximando-se da criminologia com berço nos Estados Unidos. Consequentemente, também se adere a lógica de prisão e pena como algo rentável e o privado com pseudodiscurso da dignidade ao preso começa oferecer seus serviços ao Estado. Retoma-se a ideia do grande confinamento, tão bem trabalhado por Michel Foucault em sua obra: A História da Loucura em que as instituições se propõem a prevenir

15 CHRISTIE, Nils. A industria do controle do crime. A caminho dos GULAGS em estilo ocidental. Tradução de Luis Leiria. Rio de Janeiro: Forense, 1998, p. 31.

16 CHRISTIE, Nils. A industria do controle do crime. A caminho dos GULAGS em estilo ocidental. Tradução de Luis Leiria. Rio de Janeiro: Forense, 1998, p. 38.

17 CHRISTIE, Nils. A industria do controle do crime. A caminho dos GULAGS em estilo ocidental. Tradução de Luis Leiria. Rio de Janeiro: Forense, 1998, p. 40.

18 CHRISTIE, Nils. A industria do controle do crime. A caminho dos GULAGS em estilo ocidental. Tradução de Luis Leiria. Rio de Janeiro: Forense, 1998, p. 39. 
a sociedade da desordem, confinando doentes e mendigos ${ }^{19}$.

"O sistema penal dos Estados Unidos mudou consideravelmente nos últimos dez anos", muito embora no que tange a privatização e a escravidão não tenha nada de novo. Fora com a privatização que tudo começou na Inglaterra e também nos Estados Unidos: a Promotoria era privada, a polícia era privada, as prisões municipais e os transportes também eram. Salienta-se que a principal concepção do projeto arquitetônico das prisões foi formulada por pessoas que queriam criá-las de forma lucrativa, como por exemplo: Jeremy Bentham ao desenhar o Panóptico ${ }^{20}$. Com relação a escravidão, muito embora os Estados Unidos tenham abolido, na prática, reproduziram para dentro das prisões uma espécie de aparthaid social para retirar os indesejados sociais e negros do seu meio.

Nesse contexto de leitura e reflexão sobre o sistema carcerário nos principais países do mundo, em especial naqueles considerados desenvolvidos se percebe algo em comum com a realidade brasileira; que o crime é para alguns e foi para outras sociedades uma matéria prima de controle e produto rentável ao setor privado. Para qualquer Estado manter um sistema prisional é uma conta cara, principalmente quando no seu interior estão os considerados indesejados sociais. Realmente não se sabe o que fazer para enfrentar o tema e os desafios são grandes e necessários para desconstrução daquilo que está posto. Basta saber se há essa real vontade política.

As sociedades precisam libertar-se das hipocrisias e realmente comprometerem-se com as diversidades e com o direito de respeito pelo outro. É preciso deixar de lado, a ideia de valer-se do direito para justificar condutas destruidoras e desumanizadoras de pessoas dentro do sistema prisional. Não se deseja uma sociedade que valide suas decisões na impunidade e nas segregações sociais. Sonha-se com um direito integrador e não com a lógica punitiva de esquerda, meramente reprodutora de discriminações raciais e de campos de isolamento e segregação de pobres e desempregados. O que pode se observar é que o sistema prisional é secular, que a sua política de extermínio e segregação se perpetuou até a modernidade, passando de estágios da corporificação a penas nas prisões. E ao que parece, pode continuar sendo uma promessa a pós-modernidade.

Os abolicionistas se interessam por alternativa à Política Criminal, bem como consideram que o sistema penal intervém em muitos assuntos que as pessoas envolvidas

19 CHRISTIE, Nils. A industria do controle do crime. A caminho dos GULAGS em estilo ocidental. Tradução de Luis Leiria. Rio de Janeiro: Forense, 1998, p. 80.

${ }^{20}$ CHRISTIE, Nils. A industria do controle do crime. A caminho dos GULAGS em estilo ocidental. Tradução de Luis Leiria. Rio de Janeiro: Forense, 1998, p. 140. 
não vivenciam com os delitos, esquecem da vítima no processo. Sustentam também que a intervenção do sistema penal agrava os conflitos e opera na lógica do castigo, porque impede de chegar qualquer resposta que não seja punitiva. Reconhecem que a prisão é reprodutora de criminalidade, sendo apenas uma alternativa à tortura e à pena de morte.

De igual maneira, entendem que a perspectiva penal é sempre dicotômica: brancopreto, criminoso-não-criminoso, culpado-inocente. Esse caráter binário constitui uma visão simples do homem e de seus atos, porque não permite contemplar todos os valores da coexistência humana. Em vez disso, seleciona somente aqueles que se relacionam com a $1 \mathrm{ei}^{21}$.

A natureza do movimento abolicionista é heterogênea podendo se distinguir o abolicionismo penal radical, representado por Hulsman (que propôs o desaparecimento total do sistema), e o abolicionismo institucional, limitado a alcançar a supressão da instituição do cárcere com seus anexos, como os hospitais psiquiátricos forenses ${ }^{22}$. Para muitos autores, Foucault é um precursor do abolicionismo, ou melhor, um abolicionista disfarçado. Para fundamentar isso, destacam-se idéias que ele foi expondo nas suas publicações e conferências, como sua postulada necessidade de abolir todos os limites que fixem relações assimétricas e que expressem relações de poder, porque, para ele, a abolição das desigualdades estabelece lutas locais, vinculadas a um domínio específico no qual o povo se sente oprimido ${ }^{23}$.

Além disso, os abolicionistas se valem das idéias de Foucault, como a do pensamento contínuo, aberto, sem contradição de pensamento do múltiplo ou do inacabado, idéia que é resgatada no abolicionismo por Mathiesen. Foucault sustentava que deviam ser estudados os limites da cultura, contextualizando-os constantemente com as relações de poder, desconfiando e lutando contra o que estabelecesse limites que separam o "igual” do "outro". O poder não está garantido pelo discurso formulado nas leis, mas, sim, pelo poder disciplinar, que se expressa em todas as técnicas de controle e disciplina. Esse poder disciplinar é o que produz desviados, loucos, delinqüentes etc. ${ }^{24}$

Também os abolicionistas se valem da noção da confiscação do conflito,segundo Foucault a vítima é sempre duplamente perdedora: frente ao infrator e frente ao Estado. Ela

\footnotetext{
${ }^{21}$ ELBERT, Carlos Alberto. Novo manual de criminologia. Tradução de Ney Fayet Júnior. Porto Alegre: Livraria do Advogado,2009, p.134.

${ }^{22}$ ELBERT, Carlos Alberto. Novo manual de criminologia. Tradução de Ney Fayet Júnior. Porto Alegre: Livraria do Advogado,2009, p.134.

${ }^{23}$ ELBERT, Carlos Alberto. Novo manual de criminologia. Tradução de Ney Fayet Júnior. Porto Alegre: Livraria do Advogado,2009, p.135.

${ }^{24}$ ELBERT, Carlos Alberto. Novo manual de criminologia. Tradução de Ney Fayet Júnior. Porto Alegre: Livraria do Advogado,2009, p.135.
} 
está excluída de intervir no seu próprio conflito, que é entregue a certos profissionais (confiscação). A partir dessa idéia, afirmam que a profissionalização dos que intervêm no processo penal faz com que não se escutem as pessoas verdadeiramente implicadas. Os advogados são tradutores da linguagem que se utiliza nas burocracias, ocupadas em conceder justiça. O conflito sobre o que se deve resolver desaparece quando é tratado, e os advogados são apenas tradutores do vocabulário cifrado que reduz a realidade. A busca por "uma solução" é um conceito puritano e etnocêntrico que não corresponde às experiências da vida, razão pela qual se diz que o amadurecimento se expressa na capacidade de suportar frustrações, ou seja, experiências sem solução ou sem satisfação para o indivíduo ${ }^{25}$.

Hulsman concentra-se apenas na criminalidade tradicional, diz que o cidadão médio é um mito e que, quando as pessoas compreenderem até que ponto o peso da maquinaria do castigo oprime nossas sociedades não encontrará mais ninguém a defendêla. Sustenta que a máquina de controle deve ocupar-se de $10 \%$ do total dos delinqüentes, que sejam realmente perigosos ou tenham cometido atos muito danosos. Quanto ao resto do sistema, deve ser abolido, passado para a jurisdição civil aplicando-se seus processos, mecanismos, juízes e pessoal ${ }^{26}$.

A prisão para Christie é um sofrimento não-criador, carente de sentido. As regras internas fazem prevalecer as relações de passividade, agressividade e dependênciadominação, que deixam lugar para a iniciativa nem o diálogo e alimentam o desprezo da pessoa. Na prisão se perde a personalidade e a sociabilidade e pensa-se que quem está na prisão teve o que merecia. Uma das Críticas ao modelo abolicionista aponta para a excessiva e ingênua confiança na vítima; também que o seu futuro papel protagonista (reclamado especialmente por Christie) deve ir necessariamente acompanhado de uma diminuição do poder dos órgãos estatais para impor a solução, ou seja, de um modelo de Estado diferente ${ }^{27}$.

Feito a análise do abolicionismo enquanto uma corrente de pensadores que desconstrói do imaginário social o discurso das prisões como resposta efetiva contra as condutas crimininalizantes, bem como rompe com a falácia de justiça, mister seguir a abordagem de desconstrução da Lei Maria da Penha apresentando os aspectos mais

${ }^{25}$ ELBERT, Carlos Alberto. Novo manual de criminologia. Tradução de Ney Fayet Júnior. Porto Alegre: Livraria do Advogado,2009, p.135.

${ }^{26}$ ELBERT, Carlos Alberto. Novo manual de criminologia. Tradução de Ney Fayet Júnior. Porto Alegre: Livraria do Advogado,2009, p.138.

${ }^{27}$ ELBERT, Carlos Alberto. Novo manual de criminologia. Tradução de Ney Fayet Júnior. Porto Alegre: Livraria do Advogado,2009, p.141.

Barbarói, Santa Cruz do Sul, Edição Especial n.44, p.<177-203>, jul./dez. 2015 
pontuais do crime de femicídio recorrente no Estado do Rio Grande do Sul, mesmo depois do surgimento da Lei 11.340/2006.

\section{Femicídio: aspectos relevantes ${ }^{28}$}

O "Femicídio: um tema para debate - um raio $X$ dos femicídios nos cinco anos da lei $n^{\circ} 11.340 / 06 "$ é resultado de uma pesquisa elaborada pela Secretaria de Segurança Pública do Rio Grande do Sul com intuito de diagnosticar e analisar os crimes da Lei Maria da Penha, bem como os principais problemas dos quais as mulheres são vítimas.

A violência contra a mulher é um crime aos direitos humanos e representa uma grave adversidade na sociedade. A análise dos femicídios e das circunstâncias como ocorreram são de especial importância no combate à violência doméstica e o aprimoramento da ação policial na prevenção e investigação de tais crimes. Ademais contribui para efetiva transversalidade e integração da atuação da polícia com todo sistema de justiça.

A pesquisa sobre os femicídios elaborada pela Secretaria de Segurança Pública, serviu de fundamento para proposta do Projeto Patrulha Maria da Penha. Tal estudo propôs a fomentar o enfrentamento da violência de gênero e a interrupção do ciclo de crimes. Desta forma, o estudo visa auxiliar no processo de análise, planejamento e tomada de decisão por parte das organizações públicas e privadas, pesquisadores e toda a rede de órgãos e instituições responsáveis pelo enfrentamento da violência contra a mulher.

Os dados foram obtidos por meio do Sistema Consultas Integradas da Secretaria da Segurança Pública do Estado, que permite acesso integrado às informações contidas nos bancos de dados. Outrossim, o estudo contemplou as mortes consumadas durante os cinco anos da Lei Maria da Penha no Rio Grande do Sul, no período de agosto de 2006 a agosto de 2011 .

Quanto a relação da vítima com o assassino (a) verifica-se que em quase todas as agressões domésticas, o marido ou companheiro foi o responsável pela agressão. Deste modo, ao se analisar a relação entre a vítima e o assassino, percebeu-se que "ex-maridos e ex-companheiros representam $25,5 \%$ dos criminosos, enquanto familiares totalizam $15 \%$. Juntos, os maridos e companheiros representam $50,4 \%$ ou a metade dos assassinos.

${ }^{28}$ Femicídio: um tema para debate - um raio X dos femicídios nos cinco anos da lei $\mathrm{n}^{\circ} 11.340 / 06$. In.: RIO GRANDE SO SUL. Relatório lilás. Porto Alegre: Assembléia Legislativa, 2013, p. 22-42. 
Em relação ao local do crime, o estudo apontou que em $83,48 \%$ dos casos, o assassinato ocorre na residência da própria vítima. Justifica-se este fato em razão que o femicídio é praticado de forma encoberta, na privacidade da casa e normalmente sem interrupção de outras pessoas. Esse fato confirma que é dentro do espaço doméstico familiar, que as desigualdades de gênero se desenvolvem e são reforçadas.

Em $85 \%$ dos femicídios as mulheres foram executadas com o auxílio de armas, constatou-se que a arma de fogo é o meio mais utilizado nesse tipo de crime. Do total, arma de fogo corresponde a $47 \%$ dos instrumentos, seguidos da arma branca, que corresponde a 38\%. Desse dado, constata-se a necessidade do tema arma de fogo ser incluído no debate sobre a violência doméstica.

A motivação que leva ao femicídio envolve questões afetivo-sexuais, ligadas à recusa da mulher de reatar o relacionamento, ou por vingança do parceiro por conta de separação ou ciúmes. Em conformidade a pesquisa verificou que o motivo mais frequente do femicídio é o divórcio/separação, correspondendo a 51\% das ocorrências ou mais da metade dos casos analisados. Em seguida encontram-se discussões/brigas, com $41 \%$ e em terceiro lugar, o ciúmes/traição com 5\% das situações.

Ao analisar 326 femicídios, descobriu-se que 190 ou 58,3\% delas não apresentavam registro contra o futuro assassino e 136 ou $41,7 \%$ já haviam reportado situações de violência contra ele.Importante reconhecer que a vítima possui uma relação de dependência econômica e/ou emocional com o agressor, o que a faz viver em uma relação constante de violência. Dentro desse contexto de violência constante, observa-se que a perpetuação da violência doméstica é um sistema circular.

Dentre as vítimas que já haviam registrado a violência doméstica contra outro autor, 16\% delas já haviam sofrido de 4 a 8 agressões prévias e $43 \%$ das vítimas possuíam mais de 2 agressões. Isso reforça a existência de uma espécie de "ciclo de violência" no qual a mulher está inserida antes de ser morta.

Verificou-se que em 152 casos o autor do femicídio já havia agredido outras mulheres anteriormente. Os crimes mais frequentes são a ameaça e a lesão. Este dado possui especial relevância, pois indica que a violência contra a mulher é mais ampla do que se percebe, tendo em vista que grande parte dela está oculta, transmitindo aos agressores uma falsa sensação de poder e impunidade, que vai se estendendo através das suas relações e acaba de forma trágica no assassinato.

Das vítimas que denunciaram violência praticada pelo próprio assassino, cerca de 9\% já haviam comunicado de 4 a 11 agressões prévias e $41 \%$ delas possuíam mais de 2 
agressões. Verificou-se que a cada 10 mulheres assassinadas, seis possuíam filhos com o autor do crime. Contudo, o dado mais significativo é que do total de filhos, $62 \%$ são crianças: possuem até 10 anos de idade. Se considerar os filhos de até 15 anos, chega-se ao percentual de $87 \%$. Estas crianças são vítimas invisíveis do femicídio. Razão pela qual, se verifica a necessidade de implementar políticas públicas, no sentido de amparar as crianças depois que a mãe é assassinada e o pai preso.

O gráfico abaixo, apresenta o número de femicídios no Estado do RS nos anos de 2012 , 2013 a 2014. O que preliminarmente se pode apurar é que houve um decréscimo do crime no Estado, passando de 101, 92 para 75 assassinatos. Todos os anos, o Observatório faz uma análise em cima dos dados verificados e examinados para estabelecer um perfil da vítima, bem como do agressor. Nesse contexto, a título de ilustração se buscou os dados de 2014, que representa uma redução de 25,74\% nos femicídios nesta série histórica.

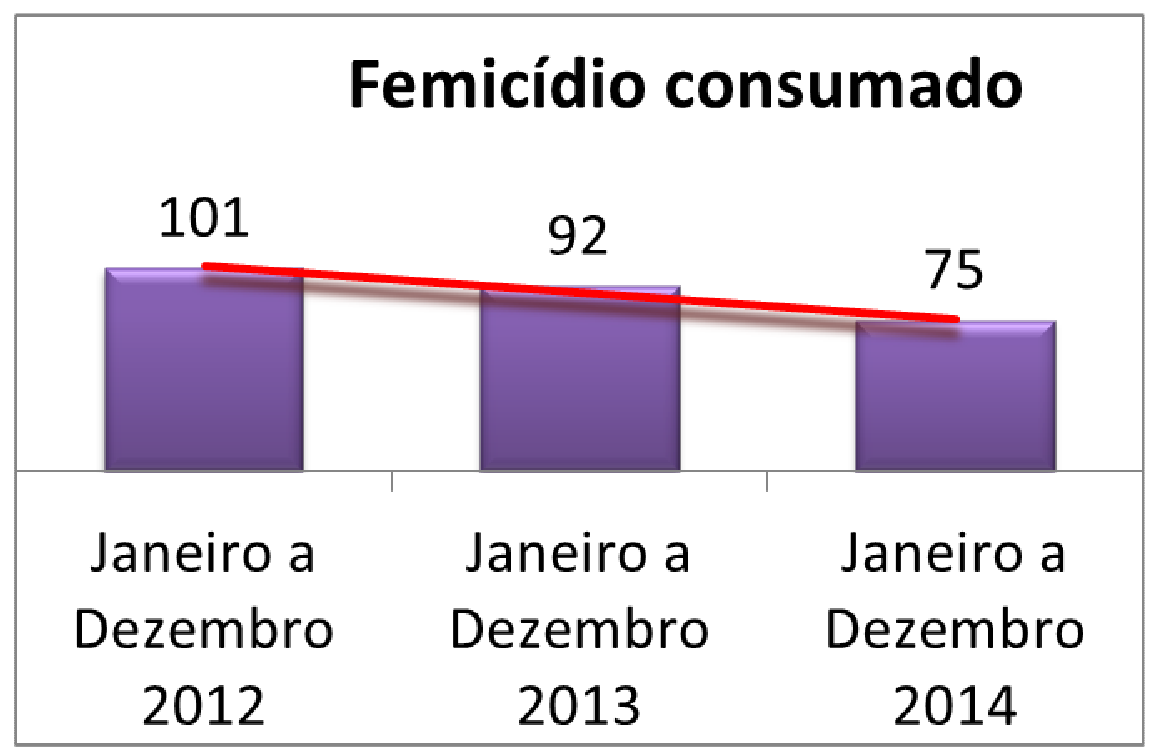

Pesquisa Perfil dos femicídios - estudo anual 2014 - Lei Maria da Penha

Com relação aos 75 feminicídios ocorridos em 2014, alguns indicadores foram observados, entre eles o turno dos crimes, sendo 33,3\% o maior índice que indica que os referidos crimes ocorreram na sua maioria a noite. É importante observar isso, pois o fato de os crimes acontecerem a noite traz uma provável evidência de que as vítimas estão mais vulneráveis, e sem condições de pedirem auxílio ou socorro a alguém, pois as demais pessoas estão recolhidas nas suas casas. Outro provável fator estava no retorno do trabalho ao ambiente doméstico em que os ânimos dos gêneros estavam alterados, por diversos fatores entre eles: instabilidade econômica, condição sociocultural, estresse da rotina laboral e da vida moderna, entre outros. 
Sobre a faixa etária do homem autor da violência de gênero, interessante o comparativo com o gráfico de 2013.

\section{Faixa Etária Autor}

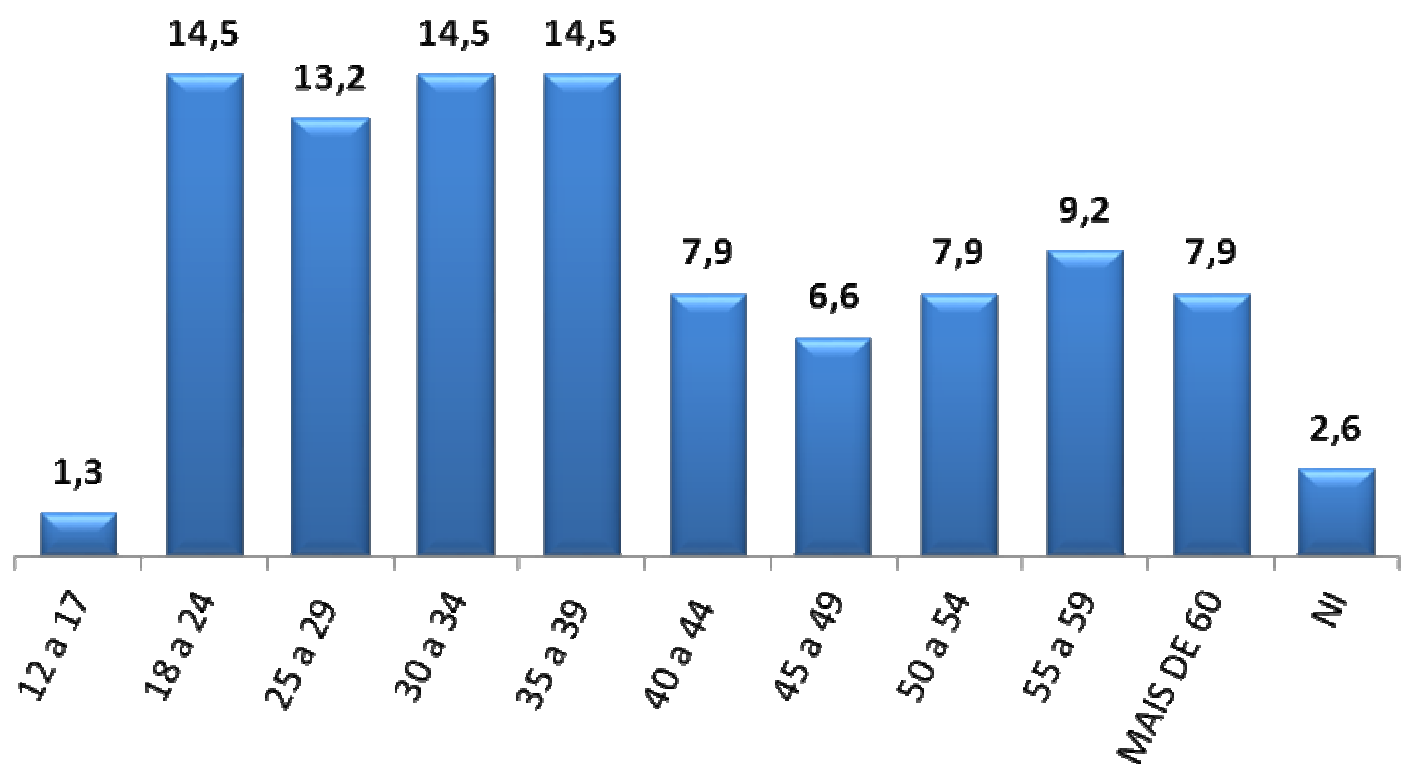

Observou-se no período de um ano, uma variação no perfil etário dos agressores. O gráfico abaixo, do perfil de 2013, mostra uma prevalência de agressores na faixa de idade entre 30 e 34 anos, já em 2014, houve uma distribuição deste critério, com o percentual maior variando entre 18 e 39 anos, assim como nas outras faixas.

Falxa Etấrla Autor - 2013

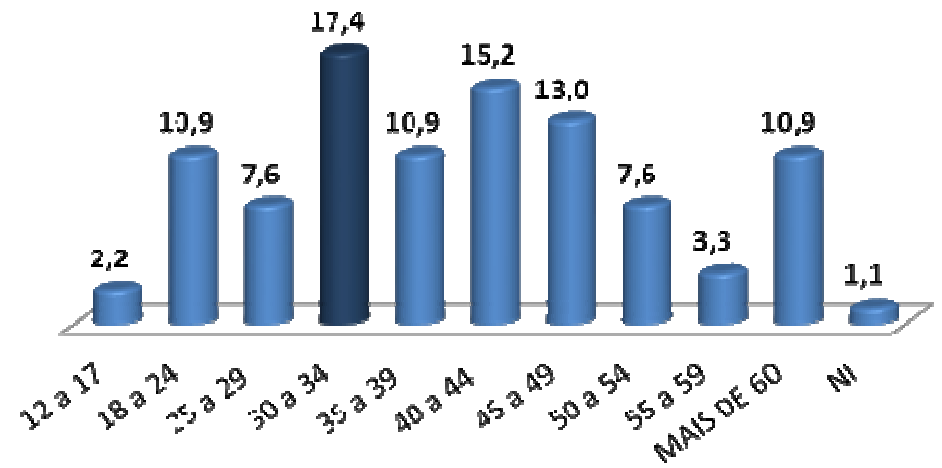

É importante avançar e levar em consideração que o agressor, independente da medida repressiva (Patrulha Maria da Penha, tornozeleiras, prisão) não inibem o sujeito de cometer o fenicídio, pois segundo estudos no RS, nem todos tem consciência de que 
realmente agiam de maneira criminosa contra suas companheiras. Culturalmente acreditam que estão as educando pela violência.

\section{Experiência do grupo de acompanhamento de homens autores de violência de gênero trabalhado no município de Bento Gonçalves ${ }^{29}$}

Durante anos, autora ficou analisando os agressores envolvidos na violência doméstica e questionando sobre a prisão deles enquanto saída para o ciclo da violência. $\mathrm{E}$ mais, se ao cumprirem a pena no presídio, saiam conscientes ou não da violência que tinham cometidos contra a suas companheiras. Durante essa experiência, compreendeu que os agressores de mulheres, diferente dos demais criminosos, não se vêem como delinquentes, mas em suas próprias palavras: "Homens trabalhadores, honestos, pais de família que apenas querem educar suas mulheres." Inúmeras ocasiões procurou convencêlos de que também eram criminosos, mas, o tempo entre saírem da viatura policial e entrarem na cela era muito pequeno para tentar explicar tamanha complexidade àquelas naturezas singulares, que portavam-se e acreditavam ser vítimas. Com o advento da Lei Maria da Penha a situação pouco mudou, a diferença é que agora os agressores de mulheres ao serem presos entendem que o ato realizado não é permitido, mas ficam inconformados e reclamam que após a instituição da referida lei, eles não podem mais "nem bater nas mulheres". Em suma, obedecem porque são obrigados, não por acreditarem ter feito algo errado ${ }^{30}$.

A partir dessa perspectiva, passou a desafiar os movimentos de mulheres em que participava e a sugerir que poder ia-se trabalhar não só com as mulheres em situação de violência, mas também com os agressores, no sentido de desconstruir suas ideias machistas e instituídas culturalmente na sociedade. No início houve muita resistência. Afinal, havia o entendimento de que os órgãos responsáveis pelo enfrentamento à violência contra a mulher deveriam atender somente as mulheres, acolhendo-as, protegendo-as e empoderando-as, já os agressores deveriam ser punidos. Ademais, no caso particular da violência contra a mulher, onde normalmente os crimes são cometidos com extrema

\footnotetext{
${ }^{29}$ TREVISAN, Isabel Pires. Experiência do grupo de acompanhamento de agressores desenvolvido em Bento Gonçalves. In: Rio Grande do Sul. Assembleia Legislativa. Comissão de Cidadania e Direitos Humanos.Relatório Lilás - 2012-2013 Porto Alegre: Assembleia Legislativa: 2013.

${ }^{30}$ TREVISAN, Isabel Pires. Experiência do grupo de acompanhamento de agressores desenvolvido em Bento Gonçalves. In: Rio Grande do Sul. Assembleia Legislativa. Comissão de Cidadania e Direitos Humanos.Relatório Lilás - 2012-2013 Porto Alegre: Assembleia Legislativa: 2013.
}

Barbarói, Santa Cruz do Sul, Edição Especial n.44, p.<177-203>, jul./dez. 2015 
crueldade, é difícil separar o profissional do ser humano e deixar de sensibilizar-se com a situação da vítima. Nesse cenário lidar com a vítima parece mais fácil ${ }^{31}$.

Mas, e com os agressores? É difícil trabalhar com eles, ouvi-los. Suas justificativas para violência contra a mulher ferem os ouvidos. Além disso, os operadores da segurança pública são capacitados para reprimir os crimes, não para educar pessoas. Esta tarefa parece estar a cargo das escolas, porém é necessário dividi-la com todos os setores da sociedade. ${ }^{32}$.

Por conta disso, a rede de atendimento à mulher em situação de violência do município reuniu-se para participar de encontros com alguns grupos de agressores. Inicialmente, foram convidados os acusados de crimes com penas de até dois anos de prisão, dentre esses delitos, os crimes mais comuns foram: ameaça perturbação da tranquilidade, injúria, calúnia, difamação e lesão corporal. Participaram das reuniões representantes de toda a rede de atendimento à mulher do município, bem como da Polícia Civil, do Ministério Público, da Defensoria Pública, do Poder Judiciário e outros ${ }^{33}$.

O que mais chamou a atenção foi a necessidade que os agressores tinham de contar a sua histoira, de justificar os seus atos. E todos, se esforçavam para mostrar que estavam corretos ao agredir as mulheres, tanto verbal como fisicamente. ${ }^{34}$.

Após ouvir os "agressores que se consideravam vítimas das mulheres", Trevisan perguntava: Tudo bem, o senhor pode ter razão, mas o senhor é feliz? Era essa a relação que tinha sonhado para a sua vida. Cada um tinha que procurar o seu caminho, desde que não fosse com violência. O mais interessante desses encontros é que após os agressores ouvirem as histórias uns dos outros, todos procuravam se ajudar mutuamente, dando opiniões, sugestões e incentivos para resolver os problemas de forma pacífica e que não tornassem a reincidir ${ }^{35}$.

\footnotetext{
31 TREVISAN, Isabel Pires. Experiência do grupo de acompanhamento de agressores desenvolvido em Bento Gonçalves. In: Rio Grande do Sul. Assembleia Legislativa. Comissão de Cidadania e Direitos Humanos.Relatório Lilás - 2012-2013 Porto Alegre: Assembleia Legislativa: 2013, p.46.

${ }^{32}$ TREVISAN, Isabel Pires. Experiência do grupo de acompanhamento de agressores desenvolvido em Bento Gonçalves. In: Rio Grande do Sul. Assembleia Legislativa. Comissão de Cidadania e Direitos Humanos.Relatório Lilás - 2012-2013 Porto Alegre: Assembleia Legislativa: 2013.

33 TREVISAN, Isabel Pires. Experiência do grupo de acompanhamento de agressores desenvolvido em Bento Gonçalves. In: Rio Grande do Sul. Assembleia Legislativa. Comissão de Cidadania e Direitos Humanos.Relatório Lilás - 2012-2013 Porto Alegre: Assembleia Legislativa: 2013.

${ }^{34}$ TREVISAN, Isabel Pires. Experiência do grupo de acompanhamento de agressores desenvolvido em Bento Gonçalves. In: Rio Grande do Sul. Assembleia Legislativa. Comissão de Cidadania e Direitos Humanos.Relatório Lilás - 2012-2013 Porto Alegre: Assembleia Legislativa: 2013,p.96.

35 TREVISAN, Isabel Pires. Experiência do grupo de acompanhamento de agressores desenvolvido em Bento Gonçalves. In: Rio Grande do Sul. Assembleia Legislativa. Comissão de Cidadania e Direitos Humanos.Relatório Lilás - 2012-2013 Porto Alegre: Assembleia Legislativa: 2013,p.96
} 
Culturalmente sempre aceitou a violência contra a mulher. Pensar do ponto de vista cultural de como mudar esse conceito é um dos caminhos para diminuir a violência, pois somente a lei e as prisões não resolvem o problema. Ao contrário, tem-se a revitimização das mulheres, porquanto seus agressores aos serem punidos sentem-se injustiçados e ao término do cumprimento de suas penas reincidem no crime, algumas vezes de forma ainda mais violenta ${ }^{36}$.

Acredita-se que uma das alternativas possíveis para o fim da violência, seja a educação tanto de homens como de mulheres, para a igualdade de gênero ${ }^{37}$.

Absorvendo a experiência desse município gaúcho, edificando o papel da operadora jurídica, que acredita no sujeito social, mais no sujeito e suas subjetividades, a grande questão do trabalho aqui está em pensar na compatibilidade das práticas restaurativas desenvolvidas na área da infância e da juventude para os casos que envolvem violência doméstica. Pode-se adiantar a dizer, que a forma trabalhada com os agressores ao gênero é uma prática restaurativa.

Para pensar sobre as subjetividades dos sujeitos, liberdade, direitos e lei, são interessantes as posições de Hobbes, J. Loke e de Montesquieu. Conforme o primeiro, quando surge a lei é porque morre o poder natural do sujeito, logo, para ele viver com o soberano, abre mão de seus poderes e capacidades, sendo lhe permitido apenas o que a lei concede e não devendo fazer o que a lei proíbe. Para o segundo pensador a subjetividade real do sujeito tão pouco aparece no direito, pois também a sua subjetividade é constituída desde a lei. E para terceiro e último, a liberdade dos seres humanos se fundamenta, a partir da segurança do ordenamento jurídico ${ }^{38}$.

A partir dessas lógicas construtivas de pensamento para avançar e desvelar a real subjetividade dos sujeitos, primeiramente é fundamental criticar, desconstruir, refletir sobre o papel do direito nas vidas humanas. Significa dizer, se realmente ele reproduz o

\footnotetext{
${ }^{36}$ TREVISAN, Isabel Pires. Experiência do grupo de acompanhamento de agressores desenvolvido em Bento Gonçalves. In: Rio Grande do Sul. Assembleia Legislativa. Comissão de Cidadania e Direitos Humanos.Relatório Lilás - 2012-2013 Porto Alegre: Assembleia Legislativa: 2013,p.95.

TREVISAN, Isabel Pires. Experiência do grupo de acompanhamento de agressores desenvolvido em Bento Gonçalves. In: Rio Grande do Sul. Assembleia Legislativa. Comissão de Cidadania e Direitos Humanos.Relatório Lilás - 2012-2013 Porto Alegre: Assembleia Legislativa: 2013.

37 TREVISAN, Isabel Pires. Experiência do grupo de acompanhamento de agressores desenvolvido em Bento Gonçalves. In: Rio Grande do Sul. Assembleia Legislativa. Comissão de Cidadania e Direitos Humanos.Relatório Lilás - 2012-2013 Porto Alegre: Assembleia Legislativa: 2013.

38 RUBIO, David Sanches. Teoría Crítica del derecho. Nuevos horizontes. San Cristóbal de Las Casas, 2013, p.146-147
}

Barbarói, Santa Cruz do Sul, Edição Especial n.44, p.<177-203>, jul./dez. 2015 
controle o possibilita a emancipação. Do mesmo modo, criticar os direitos humanos, que podem estar na mesma lógica de reprodução despótica da legalidade ${ }^{39}$.

Na mesma linha de raciocínio há de se considerar e reafirmar que a lei Maria da Penha não coíbe a violência contra mulher, pois o homem não demonstra consciência dos seus atos. Além disso, o ciclo de violência se retroalimenta, pois ambos envolvidos (o homem, a mulher e a sua família) são vítimas do contexto. Não se quer com isso, banalizar a violência, mas apenas chamar a atenção da sociedade, do poder público, que não basta pensar em condutas criminalizadoras (como criação de leis, é o que se deu com a Maria da Penha), é preciso avançar compreendendo o papel do direitosocioassistencial dos municípios. Por isso, nesses espaços e não exclusivamente os judicializados ou institucionalizados dá para construir ambientes propícios para trabalhar com a lógica dialógica -, prática restaurativa tanto com os agressores, quanto as mulheres (ofendidas), bem como seus familiares. Trabalhos em separado, enquanto um primeiro contato com a metodologia, e dependendo o caso concreto e a viabilidade, bem como a voluntariedade dos envolvidos e vitimizados pelo conflito fariam o trabalho em conjunto.

Não se tem muita experiência na área, pois a violência doméstica é complexa e quando ela torna-se visível, muitos laços foram rompidos, destruídos. De qualquer sorte, não se espera com a forma alternativa de enfrentamento ao conflito, reaproximar o casal para a convivência matrimonial; o que efetivamente se quer é que ambos percebam que é possível seguir em frente, tomar outro rumo e empoderar-se novamente das suas vidas, zelando pelas crianças, que se não acompanhadas ou assistidas acabam reproduzindo papéis, bem como o ciclo da violência para suas vidas.

Para sugerir em uma alternativa de política de justiça para o enfrentamento da violência doméstica, pensando na realidade do município de Bento Gonçalves primeiramente é preciso reconhecer que a Lei Maria da Penha está com a lógica punitiva, quando se preocupa apenas com um dos pólos: a mulher, esquecendo que o homem agressor também é uma vítima da cultura patriarcal, e que mais que responsabilizado precisa lhe ser oportunizado um processo sério e educativo.

Nesse aspecto que é possível pensar nas práticas restaurativas: nos círculos restaurativos ou de construção de paz, para que esses homens reconstruam um caminho de resignificação e compreensão, de o quanto manter a convivência com a ex-companheira não é somente violento ou destrutivo para ela, mas para ele e seus filhos.

\footnotetext{
${ }^{39}$ RUBIO, David Sanches. Teoría Crítica del derecho. Nuevos horizontes. San Cristóbal de Las Casas, 2013, p.146-147.
}

Barbarói, Santa Cruz do Sul, Edição Especial n.44, p.<177-203>, jul./dez. 2015 
Nos tempos atuais, cada vez mais tem-se buscado (re) pensar no sentido de justiça dado as relações humanas, que se quer alcançar em face a determinados conflitos sociais inerentes dos mais variados espaços ocupados pelo ser humano. Nesse viés a Justiça Restaurativa é uma possibilidade de justiça alicerçada na multiplicidade humana e valorativa, onde se propõe a restauração da responsabilidade, da liberdade e da harmonia, por meio do sentimento de pertencimento e senso de comunidade.

Não se resolvem os conflitos com a estrutura antiga, se faz necessário um espaço democrático amplo e de maior proximidade com a comunidade para juntos (poder judiciário, o município e os demais atores da rede) elaborarem as melhores estratégias de não conflituosidade Pode-se afirmar que existe uma preocupação em transformar os espaços decisórios em cenários menos burocráticos, na construção de espaços de diálogo mais democráticos ${ }^{40}$.

A Justiça Restaurativa pode ser entendida como outra maneira de se enxergar que “o sistema institucional de justiça não é senão reflexo de um padrão cultural, historicamente consensual, pautado pela crença na legitimidade do emprego da violência como instrumento compensatório das injustiças e na eficácia pedagógicas das estratégias punitivas" $"$.

Dentro desse entendimento, para alguns a Justiça Restaurativa é um processo de encontro, um método para lidar com o crime e a injustiça que inclui os interessados na decisão sobre o que efetivamente deve ser feito. Para outros, significa uma mudança na concepção de justiça, que se pretende ao ignorar o dano causado pelo delito privilegiar a reparação em detrimento da imposição de uma pena. Outros entendem que se trata de um rol de valores centrados na cooperação e na resolução do conflito, forma de concepção reparativa. "Por fim, ela busca uma transformação nas estruturas da sociedade e na forma de interação entre os seres humanos e destes com o meio ambiente." 42

Embora, a Justiça Restaurativa seja um movimento ainda novo e emergente, existe um crescente consenso internacional em relação a seus princípios, inclusive documentos da ONU e da União Européia, que validam e recomendam as práticas restaurativas para todos os países. Na Resolução no 2000/12 $2^{43}$, de 24 de julho de 2000, do Conselho Econômico e

\footnotetext{
${ }^{40}$ SALM, João; LEAL, Jackson da Silva. A Justiça Restaurativa: multidimensionalidade humana e seu convidado de honra. Disponível em: http://dx.doi.org/10.5007/2177-7055.2012v33n64p195. Acesso em: 13 jul 2013, p. 196

${ }^{41}$ ZEHR, Howard. Justiça Restaurativa.Tradução Tônia Van Acker. - São Paulo: Palas Athena, 2012, p.10.

${ }^{42}$ PALLAMOLLA, Raffaella da Porciuncula. Justiça restaurativa: da teoria à prática. 1. ed. - São Paulo : IBCCRIM, 2009, p. 59-60

43 PINTO, Renato Sócrates Gomes. Justiça Restaurativa é possível no Brasil? In: BASTOS, Márcio Thomaz;
}

Barbarói, Santa Cruz do Sul, Edição Especial n.44, p.<177-203>, jul./dez. 2015 
Social das Nações Unidas, a ONU divulga os Princípios Básicos para a Utilização de Programas de Justiça Restaurativa em Matéria Criminal. Diga-se de passagem, nas sociedades ocidentais, a Justiça restaurativa é implementada utilizando os modelos de tradições indígenas do Canadá, dos Estados Unidos e da Nova Zelândia. A partir de 1989, "a Nova Zelândia fez da Justiça Restaurativa o centro de todo o seu sistema penal para a infância e a juventude. ${ }^{44}$ "

Apesar disso, o termo "Justiça Restaurativa" recepcione uma ampla gama de programas e práticas, no seu bojo ela é um conjunto de princípios, uma filosofia, uma série alternativa de perguntas paradigmáticas, que em última análise, oferece uma estrutura alternativa para se pensar nos danos ${ }^{45}$.

Corrobora-se que a instituição de práticas restaurativas configura-se um novo olhar na esfera judiciária, nas relações familiares e comunitárias, abrindo um horizonte de participação democrática e de autonomia, ao construir espaços específicos que possibilitam o diálogo pacífico entre as partes envolvidas em um conflito. "Não raro, vítimas, ofensores e membros da comunidade sentem que o sistema deixa de atender adequadamente às suas necessidades" 46 .

Inúmeros entendimentos errôneos sobre o real sentido da Justiça Restaurativa deturpam sua aplicação, assim é fundamental definir aquilo que ela não é. A Justiça Restaurativa não tem como objeto principal o perdão ou a reconciliação, esta é uma escolha que fica totalmente a cargo dos envolvidos; a Justiça Restaurativa não é mediação, pois em um conflito mediado se presume que as partes atuem num mesmo nível ético, geralmente com responsabilidades que deverão ser partilhadas. Ainda que o termo "mediação" tenha sido adotado desde o início dentro do campo das práticas restaurativas, ele vem sendo cada vez mais substituído por termos como "encontro" ou "diálogo" 47 . Considera-se ainda que, a Justiça Restaurativa não tem por objetivo principal reduzir a reincidência ou as ofensas em série, nem é um programa ou projeto específico. "É um convite ao diálogo e à experimentação e não necessariamente uma alternativa ao aprisionamento". ${ }^{48}$

LOPES, Carlos; RENAULT, Sérgio Rabello Tamm (orgs.). Justiça Restaurativa: coletânea de artigos. Brasília: $\quad$ MJ $\quad$ E $\quad$ PNUD, $2005 . \quad$ Disponível em <http://www.undp.org/governance/docs/Justice_Pub_Restorative\%20Justice.pdf>. Acesso em: 3 out. 2009.

${ }^{44}$ ZEHR, Howard. Justiça Restaurativa.Tradução Tônia Van Acker. - São Paulo: Palas Athena, 2012, p.14.

${ }^{45}$ ZEHR, Howard. Justiça Restaurativa.Tradução Tônia Van Acker. - São Paulo: Palas Athena, 2012, p.15.

${ }^{46}$ ZEHR, Howard. Justiça Restaurativa.Tradução Tônia Van Acker. - São Paulo: Palas Athena, 2012, p.15.

${ }^{47}$ ZEHR, Howard. Justiça Restaurativa.Tradução Tônia Van Acker. - São Paulo: Palas Athena, 2012, p.1819 ..

${ }^{48}$ ZEHR, Howard. Justiça Restaurativa.Tradução Tônia Van Acker. - São Paulo: Palas Athena, 2012, p.21. 
O conceito da Justiça Restaurativa fala da justiça como valor e não apenas como instituição, e tem o foco nas necessidades determinantes e emergentes do conflito, de forma a aproximar e corresponsabilizar todos os participantes, com um plano de ações que objetiva restaurar laços familiares e sociais, compensar danos e gerar compromissos futuros mais harmônicos e uma sociedade mais segura. Baseia-se numa ética de inclusão e de responsabilidade social, no conceito de responsabilidade ativa. É essencial na aprendizagem da democracia participativa fortalecer indivíduos e comunidades para que assumam o papel de pacificarem seus próprios conflitos e assim interromper as cadeias de reprodução da violência.

Nesse sentido, a Justiça Restaurativa e suas práticas são compreendidas como moldadas dentro de um arranjo cultural mais amplo, incorporando conceitos, valores e "visões de mundo" e, ao atuarem, ajudam a gerar e a manter essas formas culturais que adotaram. Assim, a Justiça Restaurativa implementada é o resultado de um processo de lutas, alianças e transformações de aspectos culturais anteriores a sua implementação e aqueles por ela veiculados.Com isso, reconhece-se o princípio da não neutralidade, o compromisso com o resgate do tecido social por meio da resolução do conflito e o compromisso em devolver à sociedade essa resolução, pelo (re)empoderamento da fala ${ }^{49}$.

\section{Considerações finais}

Houve a preocupação em trabalhar com os principais abolicionistas penais dentro da criminologia crítica, entre eles o também filósofo Michel Foucault, com a premissa de desconstrução da efetividade do sistema prisional, relacionando a Lei Maria da Penha, que apresenta uma lógica punitiva quando se busca a referia lei para exclusivamente punir ou prender os homens autores de violência de gênero. Quando algumas mulheres enfatizam nos seus discursos o discurso da punição sem outras possibilidades de atendimento aos seus agressores; acaba se igualando em comportamento com ele, o que também é reflexo da cultura patriarcal.

Não se quer dizer com isso, que os homens autores de violência de gênero não devam ser responsabilizados pelos seus atos, pois conforme os dados sobre o femicídio levantados pela Secretaria de Segurança Pública do RS são preocupantes e merecem serem tratados

\footnotetext{
${ }^{49}$ SALM, João; LEAL, Jackson da Silva. Op. Cit., p. 200.
}

Barbarói, Santa Cruz do Sul, Edição Especial n.44, p.<177-203>, jul./dez. 2015 
com seriedade pelo Poder público e a sociedade. Aliás, a Lei 11340/2006 teve um papel preponderante enquanto política pública, pois começou a dar mais visibilidade a esta violência de ordem estrutural, simbólica e violadora dos direitos humanos dos envolvidos. Contudo, não basta aplicar a lei na busca pela punição, a envergadura precisa ir além, se trabalhando com a prevenção e idealizando uma concepção valorativa e filosófica de justiça que auxilie as pessoas a caminharem rumo a erradicação da violência, tendo por pressuposto a educação dos sujeitos para lidar com a diversidade.

\section{Referências}

BAUMAN, Zygmunt. O mal-estar da pós-modernidade. Tradução de Mauro Gama e Cláudia Martinelli Gama. Rio de Janeiro: Jorge Zahar, 1998.

BOBBIO, Norberto. Da estrutura à função: novos estudos de teoria do direito. Tradução de Daniela Beccaccia Versiani. Barueri: Manole, 2007.

BOHN, David. Diálogos. Comunicação e redes de convivência. São Paulo: Palas Athenas, 2005.

BOHN, David. Diálogos. Comunicação e redes de convivência. São Paulo: Palas Athenas, 2005.

BOURDIEU, Pierre. Razões práticas. Campinas: Papirus, 1996.

BRANCHER, Leoberto (Coord). A paz que nasce de uma justiça: Paz Restaurativa. Caxias do Sul/RS, 2013. Disponível em:

<http://www.justica21.org.br/j21.php?id=501\&pg=0\#.U6myN_ldXxU> Acesso em 24 Jun. 2014

BRANCHER, Leoberto. Artigo sobre Justiça Restaurativa. Responsabilidadesocial.com [Artigo]. Publicado em: 05/12/2009. Disponível em: $<$ http://www.responsabilidadesocial.com/article/article_view.php?id=939>. Acesso em: 27.jul.2013.

BRITZMAN, Deborah. O que é essa coisa chamada amor - identidade homossexual, educação e currículo. Educação e Realidade. Porto Alegre, v.21, n 1, p. 71-96, jan jun, 1996.

BUTLER, Judith P. Problemas de gênero: feminismo e subversão da identidade. Tradução, Renato Aguiar. Rio de Janeiro: Civilização Brasileira, 2003.

CARLOTO, Cássia Maria. Ruptura ou reforço da dominação: gênero em perspectiva. São Paulo. Prefeitura Municipal. Coordenadoria Especial da Mulher; Secretaria do Governo Municipal. Políticas públicas e igualdade de gênero / Tatau Godinho (org.). Maria Lúcia da Silveira (org.). - São Paulo: Coordenadoria Especial da Mulher, 2004. 
CHRISTIE, Nils. A industria do controle do crime. A caminho dos GULAGS em estilo ocidental. Tradução de Luis Leiria. Rio de Janeiro: Forense, 1998.

DIAS, Felipe da Veiga. COSTA, da Marli Marlene Moraes. Sistema Punitivo e Gênero. Uma abordagem alternativa a partir dos direitos humanos. Lumen Juris, Rio de Janeiro: 2013.

DUARTE, Letícia. Quando chocar é a palavra de ordem. JORNAL ZERO HORA. PROA, 22 de junho de 2014.

ELBERT, Carlos Alberto. Novo manual de criminologia. Tradução de Ney Fayet Júnior. Porto Alegre: Livraria do Advogado, 2009.

FINCO, Daniela; VIANNA Cláudia Consuelo. Meninas e meninos. In: PINTO, Graziela Pinto (coord). A mente do bebê: o fascinante processo de formação do cérebro e da personalidade. Revista. 2 ed. rev. e atual. São Paulo: Duetto, 2008.

FONSECA, Marcio Alves da. Michel Foucault e o direito. São Paulo: Max Limonad, 2002.

FOUCAULT, Michel. História da sexualidade I: a vontade de saber. 18 ed. Rio de Janeiro: Graal 2007.

FOUCAULT, Michel. Microfísica do Poder. Organização, introdução e Revisão Técnica de Roberto Machado. 27 $7^{\mathrm{a}}$ Ed. Rio de Janeiro: Graal, 2009.

FOUCAULT, Michel. Vigiar e punir: nascimento da prisão. Tradução de Raquel Ramalhete. 29. ed. Petrópoles: Vozes, 2004.

FREYRE, Gilberto. Casa-grande \& senzala: a formação da família brasileira sob o regime patriarcal. 52.ed. São Paulo : Global, 2013.

KONZEN, Afonso Armando. Justiça restaurativa e ato infracional: desvelando sentidos no itinerário de alteridade. Porto Alegre: Livraria do Advogado Editora, 2007.

MARCUSE, Herbert. A ideologia da Sociedade Industrial. O homem unidimensional. Tradução de Giasone Rebuá. 4ed. Zahar: Rio de Janeiro, 1973.

MARIOTTI, Humberto. As paixões do Ego: Complexidade, política e solidariedade. São Paulo: Palas Athenas, 2000.

PALLAMOLLA, Raffaella da Porciuncula. Justiça restaurativa: da teoria à prática. 1 . ed. - São Paulo : IBCCRIM, 2009.

PELIZOLI, Marcelo Fundamentos para a restauração da justiça. Resolução de conflitos, justiça restaurativa e a ética da alteridade/diálogo. Disponível em:

PELIZOLI, Marcelo. Fundamentos para a restauração da justiça. Resolução de conflitos, justiça restaurativa e a ética da alteridade/diálogo. Disponível em:

http://www.ufpe.br/ppgdh/images/documentos/mp_frj.pdf. Acesso em mai. 2014. 
PEREIRA DE ANDRADE, Vera Regina. Sistema Penal Máximo X Cidadania Mínima Códigos da violência na era da globalização. Editora Livraria do Advogado; Porto Alegre; 2013.

PINTO, Renato Sócrates Gomes. Justiça Restaurativa é possível no Brasil? In: BASTOS, Márcio Thomaz; LOPES, Carlos; RENAULT, Sérgio Rabello Tamm (orgs.). Justiça Restaurativa: coletânea de artigos. Brasília: MJ E PNUD, 2005. Disponível em $<$ http://www.undp.org/governance/docs/Justice_Pub_Restorative\%20Justice.pdf $>$. Acesso em: 3 out. 2009.

PINTO, Renato Sócrates. Gomes. Justiça restaurativa é possível no Brasil?. In: SLAKMON, C., De VITTO, R., PINTO, R. (Org.). Justiça Restaurativa. Brasília: Ministério da Justiça e Programa das Nações Unidas para o desenvolvimento - PUND, 2005.

PORTO, Rosane Teresinha Carvalho. A justiça restaurativa e as políticas públicas de atendimento a criança e ao adolescente no Brasil: uma análise a partir da experiência da $3^{a}$ Vara do Juizado Regional da Infância e da Juventude de Porto Alegre. Dissertação de Mestrado apresentada ao Programa de Pós-Graduação em Direito da Universidade de Santa Cruz do Sul, Santa Cruz do Sul, 2008.

PRUDENTE, Neemias Moretti.Mediación en violencia de género: no, Justicia restaurativa y mediación penal: sí. Disponível em:

$<$ http://justicarestaurativaemdebate.blogspot.com.br/2013/05/mediacion-en-violencia-degenero-no.html>. Acesso em: 20.jul.2013.

RELATÓRIO LILAS. Femicídio: um tema para debate - um raio $\mathrm{X}$ dos femicídios nos cinco anos da lei $\mathrm{n}^{\circ}$ 11.340/06. In.: RIO GRANDE SO SUL. Relatório lilás. Porto Alegre: Assembléia Legislativa, 2013.

ROSENBERG. Marshall B. Comunicação não-violenta: técnicas para aprimorar relacionamentos pessoais e profissionais; [tradução Mário Vilela]. - São Paulo: Ágora, 2006.

ROSENBERG. Marshall B. Comunicação não-violenta: técnicas para aprimorar relacionamentos pessoais e profissionais; [tradução Mário Vilela]. - São Paulo: Ágora, 2006.

RUBIO, David Sanches. Teoría Crítica del derecho. Nuevos horizontes. San Cristóbal de Las Casas, 2013.

SABADELL, Ana Lucia. Manual de Sociologia Jurídica: introdução a uma leitura externa do Direito. Revista dos Tribunais, 2008.

SALM, João; LEAL, Jackson da Silva. A Justiça Restaurativa: multidimensionalidade humana e seu convidado de honra. Disponível em: http://dx.doi.org/10.5007/21777055.2012v33n64p195. Acesso em: 13 jul 2013.

SANTANA, Selma Pereira de - Justiça Restaurativa: a reparação como consequência jurídico-penal autônoma do delito/ Selma Pereira de Santana - Rio de Janeiro: Lumen Juris, 2010. 
SANTOS, Boaventura de Sousa. Pela mão de Alice: o social e o político na pósmodernidade. 3 ed. São Paulo: Cortez, 1997.

SEN, AMARTYA. A ideia de justiça. Tradução Denise Bottmann. Ricardo Doninelli Mendes. São Paulo: Companhia das Letras, 2011.

SOARES, Vera; GODINHO, Tatau. Políticas públicas para igualdade: papel do Estado e diretrizes. Prefeitura Municipal. Coordenadoria Especial da Mulher; Secretaria do Governo Municipal. - São Paulo: Coordenadoria Especial da Mulher, 2004188 p. (Cadernos da Coordenadoria Especial da Mulher, 8 (p.127-141).

SORJ, Bernardo. A nova sociedade brasileira. Rio de Janeiro: Jorge Zahar, 2000.

SUMARIVA, Paulo. Criminologia: teoria e prática. Niterói, RJ: Impetus, 2013.

TOURAINE, Alain. O mundo das mulheres. Tradução de Francisco Morás. - Petrópolis. RJ: vozes, 2007.

TOURAINE, Alain. Pensar Outramente: o discurso interpretativo dominante. Tradução de Francisco Morás. Petrópolis, RJ: Vozes, 2009.

TOURAINE, Alain. Poderemos viver juntos? Iguais e diferentes. $2^{\text {a }}$ edição.

Petrópolis, R.J: editora Vozes,1998.

TREVISAN, Isabel Pires. Experiência do grupo de acompanhamento de agressores desenvolvido em Bento Gonçalves. In: Rio Grande do Sul. Assembleia Legislativa. Comissão de Cidadania e Direitos Humanos. Relatório Lilás - 2012-2013 Porto Alegre: Assembleia Legislativa: 2013.

VISALLI, Ugo Ottavio. El conflicto: génesis y dinámica. In: MARTÍN, Nuria Belloso. (Coordinadora) Estudios sobre mediación: la ley de mediación familiar de Castilla y León. 2006 junta de Castilla Y León. Consejería de Familia e Igualdad de Oportunidades, 2013, p. 35-49.

ZEHR, Howard. Justiça Restaurativa. Tradução Tônia Van Acker. - São Paulo: Palas Athena, 2012.

ZEHR, Howard. Trocando as lentes: um novo foco sobre o crime e a justiça - justiça restaurativa. Tradução de Tônia van Acker. São Paulo: Palas Athena, 2008.

\section{Sobre as autoras:}

Marli M. Moraes da Costa é Pós-Doutora em Direito pela Universidade de Burgos/Espanha, com Bolsa Capes. Doutora em Direito pela Universidade Federal de Santa Catarina - UFSC, professora da graduação e do Programa de Pós-Graduação em Direito - Mestrado e Doutorado na Universidade de Santa Cruz do Sul - UNISC, Professora da Graduação em Direito na FEMA - Fundação Educacional Machado de Assis de Santa Rosa, Coordenadora do Grupo de Estudos "Direito, Cidadania e Políticas 
Públicas" da UNISC. Psicóloga com Especialização em Terapia Familiar - CRP n. 07/08955, autora de livros e artigos em revistas especializadas.

Rosane Porto é Doutoranda e Mestre em Direito, área de concentração: Políticas Públicas de Inclusão Social e Especialista em Direito Penal e Processual Penal pela Universidade de Santa Cruz do Sul UNISC. Policial Militar. Professora de Direito da Infância e da Juventude, na UNISC. Estuda temáticas voltadas a Segurança Pública, criança e adolescente, criminologia, gênero e Justiça Restaurativa. Integrante do Grupo Direito, Cidadania e Políticas Públicas coordenado pela Professora Pós-Doutora Marli Marlene Moraes da Costa. 